\title{
EVALUASI PENERAPAN SISTEM PENGENDALIAN INTERNAL ATAS PENERIMAAN, PENGEMBALIAN DAN PELELANGAN BARANG JAMINAN PADA PT. PEGADAIAN (PERSERO)
}

\author{
Fifke Masyie Siwu ${ }^{1}$, Agus T. Poputra ${ }^{2}$ \\ ${ }^{1}$ Bank Mayapada, Jl. Pierre Tendean, Manado, 95111, Indonesia \\ ${ }^{2}$ Pendidikan Profesi Akuntansi, Fakultas Ekonomi dan Bisnis, Universitas Sam Ratulangi, J1. Kampus Bahu, \\ Manado, 95115, Indonesia \\ E-mail : fifkesiwu@gmail.com
}

\begin{abstract}
PT. Pegadaian (Persero) provides loans to people with require collateral item as insurance. PT. Pegadaian have to keep the collateral save and maintain it secure, so that internal control for collateral items are necessary needed. The purpose of this research was to determine and evaluate the implementation of the internal control systems for receiving, returns, and auctions of collateral items at PT. Pegadaian (Persero). The method used is qualitative descriptive with five components of COSO to evaluate the effectivities of internal control that applied at PT. Pegadaian (Persero). The five components of the COSO internal control is the control environment, risk assessment, control activities, information and communication and monitoring. The results showed that internal control systems at PT. Pegadaian (Persero) have been support by Standard Operating Procedures for all operations and filed documents. But from the evaluation for internal control system of receiving, returns, and auctions of collateral items there are still task stacking at unit manager make internal control systems PT. Pegadaian (persero) still have lack of control.
\end{abstract}

Keywords: Internal Control Systems, Collateral Item, COSO.

\section{PENDAHULUAN}

Sebagai lembaga keuangan non bank yang bergerak dalam bidang jasa kredit gadai, peran PT. Pegadaian (Persero) yang berorientasi untuk membantu dan melayani kebutuhan masyarakat berskala kecil sangat membantu pertumbuhan ekonomi. PT. Pegadaian (Persero) membantu masyarakat yang kekurangan dana untuk dapat sewaktu-waktu memenuhi kebutuhan akan uang tunai, dimana masyarakat yang membutuhkan dana dapat datang membawa barang-barang pribadinya sebagai jaminan untuk digadaikan (Siwu, 2013)

Barang jaminan merupakan salah satu persyaratan dalam mengajukan pinjaman di PT. Pegadaian (Persero). Istilah jaminan merupakan kemampuan debitur untuk memenuhi atau melunasi perutangannya kepada kreditur, yang dilakukan dengan cara menahan benda tertentu yang bernilai ekonomis sebagai tanggungan atas pinjaman atau utang yang diterima debitur tehadap krediturnya. Barang jaminan yang dapat dijadikan suatu tanggungan adalah barang yang dapat dinilai dengan uang, dapat berupa kebendaan tertentu yang diserahkan debitur kepada kreditur sebagai akibat dari suatu hubungan perjanjian hutang-piutang atau perjanjian lain.

PT. Pegadaian (Persero) memberikan pinjaman kepada masyarakat dengan mensyaratkan barang jaminan sebagai pegangannya dan melakukan pelelangan terhadap barang jaminan yang tidak dilunasi sampai batas waktu yang ditentukan. Menurut buku pedoman operasional kantor cabang PT. Pegadaian (Persero), lelang adalah upaya pengembalian uang pinjaman beserta sewa modal, yang tidak dilunasi sampai pada batas waktu yang ditentukan. Usaha ini dilakukan dengan penjualan barang jaminan tersebut kepada umum pada waktu yang telah ditentukan. 
PT. Pegadaian (Persero) wajib menyimpan dan memelihara barang jaminan serta menjaganya dari kerusakan, cacat maupun kehilangan baik sebagian maupun keseluruhannya sehingga kondisi dan nilainya tidak berkurang pada saat uang pinjaman dilunasi. Salah satu faktor terjadinya kerusakan, cacat, kehilangan barang serta berbagai macam penyimpanganpenyimpangan lainnya disebabkan lemahnya pengendalian internal khususnya pengendalian internal terhadap barang jaminan.

Pengendalian internal sangat penting untuk mencapai beberapa tujuan seperti perilaku yang efisien dan tertib dalam melaksanakan pekerjaan pegawainya, melindungi aset, pencegahan kesalahan dan mendeteksi kesalahan, pencegahan penipuan dan mendeteksi penipuan dan meningkatkan akurasi dalam kelengkapan, keandalan dan ketepatan waktu informasi yang dapat dipercaya (Topash, 2014:40). Oleh karena itu, pengendalian akan barang jaminan perlu mendapat perhatian secara proporsional dan diselenggarakan secara profesional untuk setiap barang jaminan yang ada di PT. Pegadaian (Persero).

Pentingnya sistem pengendalian internal atas barang jaminan bagi PT. Pegadaian (Persero) dalam mencapai efisiensi dan efektifitas, perlu didukung dengan evaluasi atas penerapan sistem pengendalian internalnya. Oleh karena itu, penulis tertarik untuk mengangkat hal tersebut dalam sebuah penelitian. Berdasarkan latar belakang yang telah dikemukakan sebelumnya, maka rumusan masalah pada penelitian ini adalah bagaimana penerapan sistem pengendalian internal atas penerimaan, pengembalian dan pelelangan barang jaminan pada PT. Pegadaian (Persero)?

\section{TINJAUAN PUSTAKA}

\subsection{Gadai}

PT. Pegadaian (Persero) merupakan salah satu lembaga keuangan non bank yang memberikan pinjaman kepada masyarakat dengan tujuan membantu program pemerintah dalam upaya meningkatkan kesejahteraan masyarakat khususnya golongan ekonomi menengah ke bawah melalui kegiatan penyaluran kredit gadai. Kitab Undang-undang Hukum Perdata Pasal 1150 menyatakan gadai sebagai berikut. "Gadai adalah suatu hak yang diperoleh seorang yang berpiutang atas suatu barang bergerak, yang diserahkan kepadanya oleh seorang berutang atau oleh seorang lain atas namanya, dan yang memberikan kekuasaan kepada orang berpiutang itu untuk mengambil pelunasan dari barang tersebut secara didahulukan dari pada orang yang berpiutang lainnya; dengan pengecualian biaya untuk melelang barang tersebut dan biaya yang telah dikeluarkan untuk menyelamatkannya setelah barang itu digadaikan, biaya-biaya mana harus didahulukan". Seorang debitur memberikan kekuasaan kepada kreditur untuk menggunakan barang bergerak yang telah diserahkannya, apabila debitur tidak dapat memenuhi kewajibannya pada saat jatuh tempo.

\subsection{Jaminan}

Jaminan merupakan tanggungan yang diberikan oleh debitur kepada kreditur. Bagi PT. Pegadaian (Persero), jaminan sangat berperan penting dalam proses realisasi pinjaman oleh nasabah. Menurut Bahsan (2010: 148), "jaminan adalah Segala sesuatu yang di terima kreditur dan diserahkan debitur untuk menjamin suatu utang piutang dalam masyarakat". Menurut Firdaus (2003: 252), "jaminan adalah semua barang-barang yang berwujud (tangible) yang di miliki oleh debitur maupun yang di miliki pihak lain dengan sepengetahuan dan persetujuan debitur dan diserahkan oleh debitur yang memberikan kekuasaan pada debitur untuk mengambil barang tersebut setelah di lunasi”.

Dari berbagai pengertian di atas dapat disimpulkan bahwa "jaminan merupakan suatu tanggungan yang dapat di nilai dengan uang yaitu berupa kebendaan tertentu yang diserahkan debitur kepada kreditur untuk memperoleh uang pinjaman”. 


\subsection{Sistem Pengendalian Internal}

Menurut Romney dan Steinbart (2006: 229), pengendalian internal adalah rencana organisasi dan metode bisnis yang dipergunakan untuk menjaga aset, memberikan informasi yang akurat dan andal, mendorong dan memperbaiki efisiensi jalannya organisasi serta mendorong kesesuaian dengan kebijakan yang ditetapkan. Pengendalian internal harus dilaksanakan sebaik mungkin dalam suatu perusahaan untuk mencegah dan menghindari terjadinya kesalahan, kecurangan dan penyelewengan. Pengertian lain yang diajukan oleh King yang dikutip Lakis (2012) adalah sebagai berikut.

"Internal control is a process through which the enterprise reaches its goals, results, also plans authority performance, arrangement, monitoring in the whole enterprise or separate subdivisions."

Pengendalian internal dapat juga diartikan sebagai suatu proses dimana perusahaan mencapai tujuannya, hasil, juga rencana kerja, pengaturan, pengawasan di seluruh perusahaan atau subdivisi terpisah. Selanjutnya, Committee of Sponsoring Organization of The Treadway Commission (COSO) pada tahun 1992 mengeluarkan definisi tentang pengendalian internal sebagai berikut (Provitiviti, 2014).

"Internal control is a process, effected by an entity's board of directors, management, and other personnel, designed to provide reasonable assurance regarding the achievement of objectives relating to operations, reporting and compliance."

Pengendalian internal merupakan suatu proses yang melibatkan dewan komisaris, pihak manajemen dan mereka yang berada di bawah arahan keduanya, untuk memberikan jaminan yang wajar bahwa tujuan pengendalian di capai dengan pertimbangan efektivitas dan efisiensi operasional organisasi, keandalan pelaporan keuangan, dan kesesuaian dengan hukum dan peraturan yang berlaku. Dari pengertian di atas dapat disimpulkan bahwa, sistem pengendalian internal meliputi kebijakan dan tindakan yang di ambil dalam suatu organisasi yang melibatkan pihak-pihak dalam oganisasi untuk mengatur dan mengarahkan aktivitas organisasi agar tujuan yang telah ditetapkan perusahaan tercapai.

\subsection{Komponen Sistem Pengendalian Internal COSO}

COSO adalah singkatan dari Committee of Sponsoring Organization of The Treadway Commision yaitu kelompok sektor swasta yang terdiri dari American Institute of Certified Public Accountant (AICPA), American Accounting Association (AAA), Financial Executives Internalational (FEI), The Institute of Internal Auditors (IIA) dan The Association of Accountants and Financial Professionals in Business (IMA). Tujuan utamanya adalah untuk mengidentifikasi faktor-faktor yang menyebabkan penggelapan laporan keuangan dan membuat rekomendasi untuk pengendalian, standar dan kriteria internal yang dapat digunakan perusahaan untuk menilai sistem pengendalian mereka. sistem pengendalian internal terdiri dari lima komponen adalah sebagai berikut (Provitiviti, 2014).

a. Lingkungan pengendalian (control environment)

Lingkungan pengendalian merupakan dasar untuk semua komponen pengendalian internal yang lain, menyediakan disiplin dan struktur. Lingkungan pengendalian adalah kondisi yang di bangun dan diciptakan dalam suatu organisasi yang akan mempengaruhi efektivitas pengendalian. Lingkungan pengendalian menyediakan arahan bagi organisasi dan mempengaruhi kesadaran pengendalian dari orang-orang yang ada di dalam organisasi tersebut. Lingkungan pengendalian terdiri dari faktor-faktor sebagai berikut.

1. Komitmen atas integritas dan nilai-nilai etika.

2. Filosofi pihak manajemen dan gaya beroperasi.

3. Struktur organisasi.

4. Badan audit dan dewan komisaris.

5. Metode untuk memberikan otoritas dan tanggung jawab.

6. Kebijakan dan praktik-praktik dalam sumber daya manusia. 
7. Pengaruh-pengaruh eksternal.

b. Penilaian risiko (risk assestment)

Risiko merupakan hal-hal yang berpotensi menghambat tercapainya tujuan. Identifikasi terhadap risiko (risk identification) diperlukan untuk mengetahui potensi-potensi kejadian yang dapat menghambat dan menghalangi terwujudnya tujuan organisasi. Penilaian risiko adalah identifikasi entitas dan analisis terhadap risiko yang relevan untuk mencapai tujuannya serta membentuk suatu dasar untuk menentukan bagaimana risiko harus di kelola.

c. Aktivitas pengendalian (control activities)

Aktivitas pengendalian adalah kebijakan dan prosedur yang membantu memastikan bahwa arahan manajemen dilaksanakan. Aktivitas pengendalian mempunyai berbagai tujuan dan diterapkan dari berbagai tingkat organisasi dan fungsi. Secara umum, aktivitas pengendalian terdiri dari hal-hal sebagai berikut : (1) otorisasi transaksi dan kegiatan yang memadai; (2) pemisahan tugas; (3) desain dan penggunaan dokumen serta catatan yang memadai; (4) penjagaan aset dan catatan yang memadai; dan (5) pemeriksaan independen atas kinerja.

d. Informasi dan Komunikasi (information and communication)

Informasi adalah data yang sudah di kelola yang digunakan untuk pengambilan keputusan dalam rangka penyelenggaraan tugas dan fungsi organisasi. Informasi yang salah dapat menyebabkan keputusan dan kebijakan yang salah pula. Kesalahan informasi dapat terjadi saat melakukan pengambilan data, analisis data dan kesimpulan data menjadi informasi serta pengelolaan informasi. Unsur pengendalian terhadap informasi dan komunikasi menjadi penting karena berkembangnya ilmu dan teknologi. Teknologi informasi dapat menjadikan pengendalian internal lebih efektif dan efisien, namun di sisi lain menuntut adanya pengembangan terhadap pengetahuan dan keterampilan pegawai akan teknologi informasi.

e. Pengawasan (monitoring)

Pengawasan adalah proses penentuan kualitas kinerja pengendalian internal sepanjang waktu. Pengawasan melibatkan proses yang berkelanjutan untuk menaksir kualitas pengendalian internal dari waktu ke waktu serta untuk mengambil tindakan koreksi yang diperlukan. Pengawasan dicapai melalui aktivitas yang terus-menerus (on going monitoring), evaluasi yang terpisah (separate evaluation) atau kombinasi keduanya. Aktivitas yang terus-menerus (on going monitoring) mencakup aktivitas supervisi manajemen dan tindakan lain yang dapat dilakukan untuk memastikan bahwa proses pengendalian internal secara berkelanjutan berjalan dengan efektif. Evaluasi yang terpisah (separate evaluation) adalah penilaian secara periodik atas kinerja organisasi dengan standar pengukuran yang sudah disepakati sebelumnya.

\section{METODE PENELITIAN}

\subsection{Jenis Penelitian}

Dalam penelitian ini, penulis menggunakan jenis metode penelitian deskriptif kualitatif. Penelitian dilakukan pada kondisi yang alamiah langsung ke sumber data, pengumpulan data menggunakan instrument penelitian dan data yang terkumpul berupa struktur organisasi, job description, sejarah perusahaan, jasa perusahaan serta prosedur penerimaan, pengembalian dan pelelangan barang jaminan pada PT. Pegadaian (Persero).

\subsection{Data dan Sumber Data}

Penelitian ini menggunakan data kualitatif, yaitu data yang berbentuk kata-kata, bukan dalam bentuk angka (Kuncoro, 2014). Data kualitatif yang di ambil seperti wawancara mengenai sistem informasi akuntansi dan sistem pengendalian internal atas penerimaan, pengembalian dan pelelangan barang jaminan pada PT. Pegadaian (Persero). Sumber data 
dalam penelitian ini berupa data primer dan data sekunder. Data primer didapat dengan mengumpulkannya secara langsung seperti wawancara dengan karyawan PT. Pegadaian (Persero) mengenai sistem informasi akuntansi dan sistem pengendalian internal atas penerimaan, pengembalian dan pelelangan barang jaminan serta hasil observasi akan kegiatan pengendalian internal perusahaan. Data sekunder berupa formulir, bukti, catatan maupun dokumen-dokumen perusahaan lainnya yang diperoleh dari studi kepustakaan dan dokumentasi.

\subsection{Definisi Operasional}

Agar tidak terjadi kesalahan dalam menginteprestasikan penelitian ini, maka perlu adanya beberapa definisi operasional yang relevan dipakai dalam penelitian ini, antara lain sebagai berikut.

a. Evaluasi adalah penilaian pada suatu objek dengan menggunakan suatu atau beberapa alat ukur. Dalam penelitian ini yaitu penilaian terhadap sistem pengendalian internal atas penerimaan, pengembalian dan pelelangan barang jaminan pada PT. Pegadaian (Persero) yang dibandingkan dengan lima komponen sistem pengendalian internal COSO.

b. Penerimaan yang di maksud adalah tahapan penerimaan barang jaminan dari calon nasabah kepada PT. Pegadaian (Persero) ketika mengajukan proses kredit hingga proses penyimpanan barang jaminan.

c. Pengembalian yang di maksud adalah tahapan pengembalian barang yang di mulai dari tahap pengeluaran barang jaminan dari tempat penyimpanan hingga barang jaminan diserahkan kepada nasabah ketika nasabah telah melunasi seluruh kewajibannya kepada PT. Pegadaian (Persero).

d. Lelang adalah upaya pengembalian uang pinjaman beserta sewa modal, yang tidak dilunasi sampai batas waktu yang ditentukan. Usaha ini dilakukan dengan penjualan barang jaminan tersebut kepada umum pada waktu yang telah ditentukan.

e. Sistem pengeluaran kas yang di maksud adalah hanya untuk pengeluaran kas saat kasir memberikan pinjaman kepada nasabah dan menerima barang jaminan.

f. Sistem penerimaan kas yang di maksud adalah hanya untuk penerimaan kas saat nasabah melunasi seluruh kewajibannya dan mengeluarkan barang jaminan.

g. Sistem penjualan yang dimaksud adalah penjualan saat terjadi proses lelang.

\subsection{Teknik Analisis Data}

Adapun teknik analisis data yang dilakukan adalah dengan cara sebagai berikut.

a. Mengumpulkan data kualitatif dan mempelajari penerapan sistem pengendalian internal atas penerimaan, pengembalian dan pelelangan barang jaminan pada PT. Pegadaian (Persero).

b. Mengevaluasi sistem pengendalian internal yang telah diterapkan oleh PT. Pegadaian (Persero) apakah sudah sesuai dengan komponen-komponen sistem pengendalian internal COSO.

c. Menarik kesimpulan serta memberikan saran dan masukan kepada pihak PT. Pegadaian (Persero) mengenai sistem pengendalian internal atas penerimaan, pengembalian dan pelelangan barang jaminan pada PT. Pegadaian (Persero).

\section{HASIL ANALISIS DAN PEMBAHASAN}

\subsection{Hasil Penelitian}

\section{a. Penerimaan Barang Jaminan dan Sistem Pengeluaran Kas}

Penerimaan barang jaminan di mulai dari permohonan kredit gadai oleh nasabah. Prosedur permohonan kredit gadai oleh nasabah di PT. Pegadaian (Persero) adalah sebagai berikut.

1. Nasabah

a. Nasabah datang ke kantor PT. Pegadaian (Persero). 

b. Mengambil dan mengisi Formulir Permintaan Kredit (FPK).
c. Menyerahkan Formulir Permintaan Kredit yang telah di isi dengan melampirkan foto copy Kartu Tanda Pengenal (KTP), Surat Izin Mengemudi (SIM) atau paspor yang masih berlaku serta Barang Jaminan (BJ) yang akan dijaminkan.
d. Menandatangani Surat Bukti Kredit (SBK) asli dan dwilipat yang diserahkan oleh kasir dan menyerahkan kembali SBK dwilipat kepada kasir.
e. Menerima uang pinjaman dan SBK asli (lembar 1).

2. Penaksir, Penyimpan dan Pengelola UPC.
a. Menerima FPK dengan lampiran KTP, SIM atau paspor beserta BJ dari nasabah.
b. Memeriksa kelengkapan kebenaran pengisian FPK dan BJ yang dijaminkan.
c. Memeriksa dan mencocokkan foto copy identitas nasabah dengan asli.
d. Menandatangani FPK sebagai tanda bukti penerimaan BJ dari nasabah.
e. Melakukan taksiran untuk menentukan nilai BJ.
f. Memutuskan besarnya Uang Pinjaman yang dapat diberikan kepada nasabah sesuai dengan ketentuan yang berlaku.
g. Menyerahkan FPK yang telah ditandatangani kepada kasir.
h. Melakukan penyimpanan Barang jaminan dengan melampirkan kitir SBK di Barang Jaminan.

3. Kasir

a. Menerima FPK dari penaksir atau pengelola UPC.

b. Membuat SBK berdasarkan FPK.

c. Melaksanakan pembayaran kredit gadai dan menerima dwilipat dan kitir SBK yang telah ditandatangani nasabah.

d. Menyimpan dwilipat SBK sebagai administrasi.

e. Menyerahkan kitir SBK kepada penaksir atau pengelola UPC sebagai lampiran di BJ. Jurnal pada saat penerimaan jaminan dan pengeluaran kas pada PT. Pegadaian (Persero) sebagai berikut.

Rekening Nominatif Nasabah

Pendapatan Administrasi Golongan x

$\mathrm{XXX}$

Kas Kecil Kasir

$\mathrm{XXX}$

Pendapatan Sewa Modal yang Masih Harus Diterima

Pendp. Sewa Modal Golongan x

$\mathrm{XXX}$
$\mathrm{XXX}$

\section{b. Pengembalian Barang Jaminan dan Sistem Penerimaan Kas}

Pengembalian barang jaminan di mulai dari prosedur pelunasan kredit gadai oleh nasabah. Prosedur pelunasan kredit gadai oleh nasabah di PT. Pegadaian (Persero) adalah sebagai berikut.

1. Nasabah

a. Menyerahkan Surat Bukti Kredit (SBK) asli, Kartu Tanda Penduduk (KTP) asli dan foto copy serta sejumlah uang untuk pelunasan sesuai dengan jumlah yang harus di bayar kepada kasir.

b. Menerima Slip Pelunasan (SP) lembar 1 sebagai bukti pelunasan.

c. Menerima barang jaminan yang telah di lunasi.

2. Kasir

a. Menerima SBK asli, KTP asli dan foto copy dan mencocokkan untuk keabsahan.

b. Melakukan penghitungan jumlah uang pelunasan yang harus di bayar nasabah yaitu pokok pinjaman dan sewa modal.

c. Menerima pembayaran dari nasabah.

d. Menerbitkan dan menyerahkan Slip Pelunasan lembar 1 kepada nasabah sebagai tanda bukti pelunasan dan Slip Pelunasan lembar 2 sebagai arsip.

e. Membubuhkan cap lunas, tanggal dan paraf pada SBK asli. 
f. Mengarsip SBK asli, SBK kitir, foto copy KTP, Slip Pelunasan lembar 2 dan Formulir Permintaan Kredit.

3. Penyimpan, Pengelola UPC.

a. Menerima Surat Bukti Kredit asli dan memeriksa cap lunas, tanggal dan paraf kasir.

b. Mencocokkan Surat Bukti Kredit asli dengan nomor kitir yang menempel di barang jaminan. Apabila sudah cocok, serahkan barang jaminan kepada nasabah.

c. Pada akhir jam tutup kantor mencocokkan jumlah seluruh barang jaminan yang di tebus pada hari itu dengan mencocokkan jumlah penerimaan Surat Bukti Kredit asli yang di terima dari nasabah dengan rekapitulasi pelunasan yang di buat.

d. Mencatat ke dalam formulir yang terkait.

Pencatatan akuntansi untuk proses pengembalian barang jaminan karena adanya pelunasan kredit adalah sebagai berikut.

1. Saat Pelunasan Kredit sebelum Jatuh Tempo.

Kas Kecil Kasir

Rekening Normatif Nasabah

Pendp. Sewa Modal Golongan x

Pendp. Sewa Modal Golongan x

Pendapatan Sewa Modal YMHD

2. Saat Pelunasan Kredit setelah Jatuh Tempo.

Kas Kecil Kasir

Rekening Normatif Nasabah

Pendp. Sewa Modal Golongan x

Pendp. Sewa Modal Tambahan Gol. X

Pendp. Sewa Modal Golongan x

Pendapatan Sewa Modal YMHD
XXX

$\mathrm{XXX}$

$\mathrm{XXX}$

XXX

XXX

XXX

$\mathrm{XXX}$

$\mathrm{XXX}$

$\mathrm{XXX}$

$\operatorname{XXX}$

$\operatorname{XXX}$

\section{c. Pelelangan Barang Jaminan dan Sistem Penjualan}

Pelelangan barang jaminan adalah upaya yang dilakukan PT Pegadaian (Persero) untuk mengembalikan modal dengan cara menjualnya ke masyarakat umum ketika nasabah tidak dapat melunasi pinjaman saat telah jatuh tempo. Pelelangan dilaksanakan oleh tim pelaksana lelang yang ditunjuk langsung oleh kepala cabang. Prosedur pelelangan barang jaminan di PT. Pegadaian (Persero) adalah sebagai berikut.

1. Nasabah

a. Nasabah menerima informasi dari pihak PT. Pegadaian (Persero) mengenai batas akhir pelunasan pinjaman. Biasanya nasabah dihubungi satu minggu sebelum tanggal jatuh tempo.

b. Apabila penjualan barang jaminan melebihi kewajiban nasabah (uang pinjaman, sewa modal, bea lelang), maka nasabah berhak mengambil kelebihan tersebut.

c. Menyerahkan Surat Bukti Kredit (SBK) asli dan bukti identitas KTP, SIM atau Paspor saat pengambilan kelebihan uang hasil pelelangan.

2. Penyimpan, Pengelola UPC

a. Mengeluarkan dan menyiapkan barang jaminan yang akan dilelang.

b. Membuat Berita Acara Penyerahan Barang Jaminan (BAPBJ) dan mencatat pengeluaran barang jaminan di buku gudang.

c. Menyerahkan BAPBJ dan barang jaminan ke pelaksana lelang.

d. Menerima dan menyimpan barang jaminan yang tidak laku dari pelaksana lelang dan mencocokkan dengan register barang sisa lelang.

3. Pelaksana Lelang.

a. Menerima barang jaminan dan BAPBJ dari penyimpan atau pengelola UPC.

b. Membuat Daftar Barang Jaminan yang akan dilelang (DBJYAD).

c. Memeriksa barang jaminan dengan BAPBJ yang diterima. 
d. Menetapkan harga penjualan lelang.

e. Setelah selesai lelang, membuat dan menandatangani Berita Acara Lelang (BAL) dan Laporan Daftar Penjualan Lelang (LDPL) dan uang hasil penjualan lelang. Untuk barang jaminan yang tidak laku saat pelelangan dicatat pada Register Barang Sisa Lelang (RBSL).

f. Menyerahkan barang jaminan yang tidak laku ke penyimpan atau pengelola UPC untuk disimpan kembali.

4. Kasir, Administrasi.

a. Menerima BAL, RBSL dan uang hasil penjualan lelang dari pelaksana lelang.

b. Berdasarkan BAL dan uang hasil penjualan lelang yang diterima dicatat pada Laporan Harian Kas (LHK).

c. Mencatat nomor barang jaminan yang telah dilelang dan membuat buku penjualan lelang.

d. Membayar uang sisa lelang kepada nasabah.

Pencatatan akuntansi untuk proses pelelangan barang jaminan diawali dari pembelian barang jaminan oleh pegadaian karena gagal lunas. Barang jaminan akan dicatat sebagai Barang Lelang Perusahaan (BLP). Ayat jurnal yang dicatat untuk transaksi pembelian barang jaminan oleh pelelangan karena gagal lunas adalah sebagai berikut.

$\begin{array}{lr}\text { BLP golongan } \mathrm{x} & \mathrm{xxx} \\ \text { Rekening Normatif Nasabah } & \mathrm{xxx} \\ \text { Pendapatan Sewa Modal Golongan } \mathrm{x} & \mathrm{xxx} \\ \text { Bea Lelang } & \mathrm{xxx}\end{array}$

Ketika BLP laku terjual maka pegadaian akan mencatat jurnal untuk penjualan BLP. Selain itu, pegadaian harus menyetor bea lelang dari hasil penjualan tersebut sebesar $2 \%$. Berikut ayat jurnal yang digunakan untuk mencatat transaksi tersebut.

1. Jurnal untuk mencatat penjualan BLP

Kas

$\mathrm{XXX}$

(Rugi periode berjalan

$\mathrm{XXX})$

BLP Golongan $x$

$\mathrm{XXX}$

(Laba periode berjalan

$\mathrm{XXX})$

2. Jurnal untuk mencatat penyetoran Bea Lelang ke Kas Negara

Bea Lelang

XXX

Kas

$\operatorname{XXX}$

\subsection{Pembahasan}

Suatu pengendalian internal dikatakan efektif apabila memahami tingkat sejauh mana tujuan operasi entitas tercapai, laporan keuangan yang diterbitkan dipersiapkan secara handal, hukum dan regulasi yang berlaku dipatuhi (Akwaa, 2016). Hasil penelitian menunjukkan bahwa penerimaan, pengembalian, dan pelelangan barang jaminan pada PT. Pegadaian (Persero) telah dilakukan berdasarkan prosedur standar PT. Pegadaian (Persero) dan pencatatan akuntansinya dilakukan dengan sistem. Sistem pengendalian internal yang efisien dapat dinilai dengan menggunakan lima komponen COSO dikenal juga dengan COSO framework) dalam mengevaluasi pengendalian internal perusahaan. Lima komponen COSO tersebut adalah control environment, risk assessment, control activities, information and communication, dan monitoring (Oseifuah, 2015).

a. Evaluasi Sistem Pengendalian Internal atas Penerimaan Barang Jaminan dan Sistem Pengeluaran Kas

Berdasarkan hasil penelitian pada sistem penerimaan barang jaminan dan sistem pengeluaran kas, maka evaluasi sistem pengendalian internal atas penerimaan barang jaminan dan sistem pengeluaran kas dengan mempertimbangkan lima komponen COSO adalah sebagai berikut. 
1. Lingkungan pengendalian (control environment). Proses menaksir emas hanya dilakukan oleh karyawan yang memiliki keahlian dan kompetensi sebagai seorang penaksir. Budaya kerja dari PT. Pegadaian (Persero) dikenal istilah INTAN. Setiap karyawan memiliki tanggung jawab dan job description masing-masing. Otorisasi atas dokumen surat bukti kredit pada tingkat pengelola UPC hanya dilakukan oleh satu karyawan saja dan adanya rangkap jabatan dimana pengelola UPC merangkap fungsi sebagai penaksir dan fungsi penyimpan barang jaminan. Barang jaminan yang telah ditaksir disimpan pada saat tutup kantor dan dilakukan pengecekan kembali berdasarkan laporan rekapitulasi pinjaman.

2. Penilaian resiko (risk assestment). Dalam penilaian resiko terhadap penerimaan barang jaminan PT. Pegadaian (Persero) membekali fungsi penaksir dengan pelatihan khusus dan memiliki panduan dalam melakukan penaksiran sehingga fungsi penaksir dapat membedakan mana jaminan yang benar-benar emas dan tidak. Dalam penyimpanan PT. Pegadaian (Persero) menyimpan barang jaminan ditempat khusus, tahan api dan dilengkapi dengan kamera pengawas, dan kunci brangkas disimpan oleh karyawan yang memiliki wewenang.

3. Aktivitas pengendalian (control activities). Dalam melaksanakan penerimaan barang jaminan dan sistem pengeluaran kas pihak-pihak yang terkait adalah pengelola UPC dan kasir. Dokumen-Dokumen yang terkait dalam prosedur penerimaan barang jaminan adalah formulir permintaan kredit (FPK), surat bukti kredit (SBK), buku gudang (BG) dan buku penerimaan barang jaminan (BPBJ). Seluruh dokumen yang berkaitan dengan penerimaan barang jaminan dan penerimaan kasi disimpan dalam brangkas tahan api dan dijaga kerahasiaan nasabahnya. Fungsi penaksir dan otorisasi dalam penerimaan barang jaminan dilakukan oleh pengelola UPC dan pengeluaran kas dilakukan oleh bagian kasir.

4. Informasi dan komunikasi (Information and communication). PT. Pegadaian (Persero) menggunakan sistem yang telah terkomputerisasi sehingga dalam membuat laporan tidak membutuhkan waktu yang lama dan informasinya lebih dapat diandalkan. Laporan akuntansi dapat di buat oleh pegawai PT. Pegadaian (Persero) dengan mencetak laporan yang ada di sistem. Laporan akuntansi yang di hasilkan dalam prosedur penerimaan barang jaminan dan sistem pengeluaran kas adalah laporan pinjaman (LP), laporan harian kas (LHK), laporan rekapitulasi pinjaman (LRP). laporan ikhtisar pinjaman dan pelunasan (IPP).

5. Pengawasan (monitoring). Proses pengawasan pada penerimaan barang jaminan dan sistem pengeluaran kas dilakukan dengan cara adanya penaksiran kembali untuk jaminan emas setiap sebulan sekali oleh pimpinan cabang sehingga dapat diawasi apabila penaksir melakukan kesalahan dalam menaksir dan adanya pengawasan dari pihak satuan pengawas internal (SPI) PT. Pegadaian (Persero) yang melakukan audit setiap enam bulan sekali.

Suatu transaksi yang terjadi dalam perusahaan tidak boleh dilakukan oleh satu fungsi saja, namun harus ada campur tangan dari fungsi lainnya. Suatu fungsi tidak boleh diberikan tanggung jawab penuh untuk melaksanakan semua tahap suatu transaksi. Pengendalian yang baik harus ada pemisahan tugas yang dilakukan pada tingkatan yang berbeda dalam suatu proses bisnis (Teru, 2015:3). Hasil evaluasi sistem pengendalian internal atas penerimaan barang jaminan dan sistem pengeluaran kas yang dilakukan di PT. Pegadaian (Persero) menunjukkan bahwa setiap fungsi dilakukan oleh karyawan yang berbeda-beda. Sedangkan untuk unit pelayanan cabang (UPC), pengelola UPC merangkap jabatan sebagai penaksir dan penyimpan barang jaminan dan bagian kasir merangkap jabatan sebagai kasir dan administrasi. Hal ini bertentangan dengan sistem pengendalian internal COSO, terutama pada komponen aktivitas pengendalian yang mengharuskan adanya 
pemisahan tugas (Provitiviti, 2014). Berdasarkan pada evaluasi sistem pengendalian internal atas penerimaan barang jaminan dan sistem pengeluaran kas, maka dapat dirangkumkan beberapa kelebihan dan kekurangan dari sistem pengendalian internal yang sudah ada.

1. Kelebihan dari sistem pengendalian internal atas prosedur penerimaan barang jaminan dan sistem pengeluaran kas pada PT. Pegadaian (Persero).

a. Brangkas hanya boleh di buka oleh karyawan yang memiliki otoritas untuk menyimpan barang jaminan.

b. Sering dilakukan perhitungan dan pemeriksaan fisik barang jaminan setiap bulannya oleh petugas yang berwenang.

c. Tempat penyimpanan barang jaminan berupa gudang barang jaminan telah dilengkapi dengan sistem keamanan yang baik.

d. Adanya laporan dan dokumen yang mendukung setiap prosedur penerimaan barang jaminan.

2. Kelemahan dari sistem pengendalian internal atas prosedur penerimaan barang jaminan dan sistem pengeluaran kas pada PT. Pegadaian (Persero).

a. Khusus UPC, masih ada rangkap jabatan yaitu penaksir, pemegang gudang dan penyimpan barang jaminan hanya dilakukan oleh satu orang saja yaitu pengelola UPC.

b. Khusus UPC, sistem otorisasi kurang memadai karena tiap dokumen hanya di otorisasi oleh satu pejabat berwenang saja dan bukan oleh dua pejabat berwenang yaitu hanya dilakukan otorisasi oleh pengelola UPC.

c. Dalam prakteknya, barang jaminan seringkali tidak di simpan ke dalam gudang setelah terjadi proses penerimaan barang jaminan dan hanya dibiarkan di dalam laci. Hal ini memungkinkan terjadinya penyimpangan atau kehilangan barang jaminan.

\section{b. Evaluasi Sistem Pengendalian Internal atas Pengembalian Barang Jaminan dan} Sistem Penerimaan Kas

Berdasarkan hasil penelitian pada pengembalian barang jaminan dan sistem penerimaan kas, maka evaluasi sistem pengendalian internal atas pengembalian barang jaminan dan sistem penerimaan kas dengan mempertimbangkan lima komponen COSO adalah sebagai berikut.

1. Lingkungan pengendalian (control environment). Barang jaminan akan dikeluarkan oleh fungsi penyimpan ketika nasabah telah melunasi seluruh pinjamannya dan pengambilan barang jaminan oleh nasabah harus dilakukan oleh nasabah tersebut, tidak bisa diwakili dan harus melampirkan tanda bukti pengenal dan membawa surat bukti kredit. Adanya pembagian tugas yang jelas antara fungsi penyimpan dan fungsi kasir. Pengembalian barang jaminan diatur berdasarkan standar pedoman operasional kantor cabang PT. Pegadaian (Persero). Surat bukti kredit yang diberikan nasabah pada saat pengambilan jaminan akan diarsip sebagai bukti telah dilakukannya pengembalian barang jaminan oleh nasabah.

2. Penilaian resiko (risk assestment). Dalam penilaian resiko terhadap pengembalian barang jaminan PT. Pegadaian (Persero) dimana nasabah harus datang langsung dan membawa tanda pengenal dan surat bukti kredit ketika melakukan pengambilan barang jaminan. Pengambilan barang jaminan dari dalam brangkas hanya boleh dilakukan oleh fungsi penyimpan.

3. Aktivitas pengendalian (control activities). Pengembalian barang jaminan dilakukan oleh fungsi penyimpan namun untuk kantor UPC dikarenakan pengelola UPC merangkap jabatan sebagai fungsi penyimpan maka pengambilan jaminan dari dalam brangkas dilakukan oleh pengelola UPC. Untuk menjaga keakuratan informasi maka 
dalam pelunasan pinjaman nasabah wajib membawa kartu tanda pengenal. Seluruh proses pengembalian barang jaminan dan penerimaan kas diatur dalam buku pedoman operasional kantor cabang PT. Pegadaian (Persero).

4. Informasi dan komunikasi (Information and communication). Informasi bagi pihak manajemen berupa laporan akuntansi, laporan akuntansi yang di hasilkan dalam prosedur pengembalian barang jaminan dan sistem penerimaan kas adalah laporan pinjaman (LP), laporan harian kas (LHK), laporan pelunasan (LP), laporan rekapitulasi pelunasan (LRP), laporan ikhtisar pinjaman dan pelunasan (IKP).

5. Pengawasan (monitoring). Proses pengawasan pada pengembalian barang jaminan dan sistem penerimaan kas adanya dua fungsi yang berbeda yang memeriksa keabsahan dokumen nasabah yang melakukan pelunasan pinjaman yaitu fungsi kasir dan fungsi penyimpan. Setiap harinya dibuat laporan rekapitulasi pelunasan dan laporan harian kas sehingga pimpinan dapat melakukan pengecekan terhadap besarnya pelunasan dan besarnya penerimaan kas.

Hasil evaluasi sistem pengendalian internal atas pengembalian barang jaminan dan sistem penerimaan kas yang dilakukan di PT. Pegadaian (Persero) menunjukkan bahwa pengendalian internal untuk pengembalian barang jaminan dan sistem penerimaan kas pada unit pelayanan cabang (UPC) kurang baik. Hal ini dikarenakan pengelola UPC merangkap jabatan sebagai penyimpan barang jaminan dan bagian kasir merangkap jabatan sebagai kasir dan administrasi. Sekali lagi, hal ini bertentangan dengan sistem pengendalian internal COSO, terutama pada komponen aktivitas pengendalian yang mengharuskan adanya pemisahan tugas (Provitiviti, 2014). Berdasarkan pada evaluasi sistem pengendalian internal atas pengembalian barang jaminan dan sistem penerimaan kas, maka dapat dirangkumkan beberapa kelebihan dan kekurangan dari sistem pengendalian internal yang sudah ada.

1. Kelebihan dari sistem pengendalian internal atas pengembalian barang jaminan dan sistem pengeluaran kas pada PT. Pegadaian (Persero).

a. Brankas hanya boleh di buka oleh karyawan yang memiliki otoritas untuk mengambil barang jaminan.

b. Barang jaminan hanya bisa diambil oleh nasabah yang menggadaikannya, tidak bisa diwakili dan harus menyertakan tanda pengenal.

c. Adanya laporan dan dokumen yang mendukung setiap prosedur pengembalian barang jaminan.

2. Kelemahan dari sistem pengendalian internal atas prosedur pengembalian barang jaminan dan sistem penerimaan kas pada PT. Pegadaian (Persero).

a. Khusus UPC, masih ada rangkap jabatan yaitu pemegang gudang dan penyimpan barang jaminan hanya dilakukan oleh satu orang saja yaitu pengelola UPC.

b. Khusus UPC, sistem otorisasi kurang memadai karena tiap dokumen hanya di otorisasi oleh satu pejabat berwenang saja dan bukan oleh dua pejabat berwenang yaitu hanya dilakukan otorisasi oleh pengelola UPC.

c. Kasir yang rangkap jabatan dengan urusan administrasi dapat membuat lemahnya pengendalian internal khususnya dalam prosedur penerimaan kas pada tingkat UPC.

\section{c. Evaluasi Sistem Pengendalian Internal atas Pelelangan Barang Jaminan}

Berdasarkan hasil penelitian pada sistem pengendalian internal pelelangan barang jaminan dan sistem penjualan, maka evaluasi sistem pengendalian internal atas pelelangan barang jaminan dan sistem penjualan dengan mempertimbangkan lima komponen COSO adalah sebagai berikut.

1. Lingkungan pengendalian (control environment). Sesuai dengan ketentuan PT. Pegadaian (Persero) proses pelelangan barang jaminan hanya dilakukan untuk barang 
jaminan yang telah jatuh tempo dan hingga periode tertentu nasabah belum bisa melunasinya. Pelaksanaan pelelangan dilakukan oleh pelaksana lelang yang terdiri dari beberapa orang dan memiliki surat keputusan sebagai pelaksana lelang dan setiap pelaksana lelang harus melakukan otorisasi untuk setiap laporan pelelangan yang dibuat.

2. Penilaian resiko (risk assestment). Untuk meminimalisir kerugian akibat kredit macet, PT. Pegadaian (Persero) menggunakan sistem lelang sehingga dana hasil penjualan jaminan diharapkan dapat menutupi besarnya jaminan dan bunga pinjaman.

3. Aktivitas pengendalian (control activities). Sebelum melakukan pelelangan, barang jaminan ditaksir kembali oleh pelaksana lelang sesuai dengan ketentuan dari PT. Pegadaian (Persero). Penaksiran kembali dilakukan oleh pelaksana lelang dan setiap pelaksana lelang memiliki tanggung jawab terhadap proses lelang dan barang jaminan yang dilelang. Barang jaminan yang telah keluar dari brangkas dicatat dan hasil penjualan barang jaminan disetor kepada kasir pada akhir hari pelelangan apabila hasil lelang setelah dikurangi dengan uang pinjaman, bunga pinjaman dan biaya lelang memiliki hasil lebih maka hasil tersebut akan dikembalikan kepada nasabah.

4. Informasi dan komunikasi (Information and communication). Sebelum barang jaminan akan dilelang PT. Pegadaian (Persero) telah menghubungi pihak nasabah mengenai jatuh tempo pembayaran dan tenggang waktu yang diberikan untuk pembayaran pinjaman, apabila hingga tenggang waktu tersebut nasabah tidak datang untuk membayar pinjaman maka PT. Pegadaian (Persero) akan melaksanakan proses lelang. Pada saat terjadi pelelangan tidak adanya dokumen yang diserahkan kepada pihak pembeli sehingga tidak ada bukti pendukung pada saat terjadi proses penjualan dan penerimaan uang dari pembeli, namun laporan keuangan saat pelelangan tetap dibuat yaitu laporan daftar penjualan lelang (LDPL) yang dibuat oleh pelaksana lelang, memuat masing-masing barang jaminan yang laku terjual. Seringkali dalam proses lelang ada jaminan yang tidak laku terjual maka prosedur untuk barang lelang yang tidak laku adalah sebagai berikut.

a. Untuk barang jaminan lelang yang tidak laku terjual pada saat waktu pelelangan maka barang tersebut dikategorikan sebagai barang lelang ulang (BLU) yang akan dimasukkan kedalam daftar register ulang lelang dan barang tersebut hanya diperbolekan untuk penjualan lelang ulang hanya satu kali pada periode lelang tersebut (harus bisa terjual).

b. Apabila pada lelang periode berikutnya BLU masih tidak laku dilelang maka diusulkan untuk dilakukan pengajuan penurunan harga jual lelang kepada pejabat terkait sehingga barang jaminan lelang dapat laku terjual.

5. Pengawasan (monitoring). Proses pengawasan pada pelelangan barang jaminan dan sistem penjualan dilakukan dengan cara dibentuknya pelaksana lelang yang terdiri dari ketua dan beberapa anggota yang memiliki tanggung jawab terhadap barang jaminan yang akan dilelang dan sebelum pelaksanaan lelang, pelaksana lelang akan melakukan penaksiran kembali.

Berdasarkan pada evaluasi sistem pengendalian internal atas pelelangan barang jaminan dan sistem penjualan, maka dapat dirangkumkan beberapa kelebihan dan kekurangan dari sistem pengendalian internal yang sudah ada.

1. Kelebihan dari sistem pengendalian internal atas pelelangan barang jaminan dan sistem penjualan pada PT. Pegadaian (Persero).

a. Dibentuknya pelaksana lelang yang terdiri dari ketua dan anggota pelaksana lelang.

b. Sebelum barang jaminan dilelang PT. Pegadaian (Persero) menghubungi nasabah untuk memberitahukan jatuh tempo pembayaran pinjaman. 

c. Barang jaminan ditaksir kembali sebelum dilaksanakan proses lelang.
d. Setiap pelaksana lelang harus mengotorisasi dokumen dan laporan yang dibuat dalam proses lelang.

2. Kelemahan dari sistem pengendalian internal atas pelelangan barang jaminan dan sistem penjualan pada PT. Pegadaian (Persero).

a. Tidak adanya dokumen yang diberikan kepada pembeli ketika barang jaminan terjual.

b. Tidak adanya dokumen yang diberikan kepada nasabah sebagai bukti barang sudah dilelang dan nasabah tidak mengetahui berapa besarnya harga yang terjual saat pelelangan barang jaminan.

\section{KESIMPULAN DAN SARAN}

\subsection{Kesimpulan}

Berdasarkan hasil pembahasan mengenai evaluasi penerapan sistem pengendalian intern atas penerimaan, pengembalian dan pelelangan barang jaminan pada PT. Pegadaian (Persero) dengan menggunakan lima komponen COSO, dapat disimpulkan sebagai berikut.

a. Pengendalian internal yang sudah ada di PT. Pegadaian (Persero) telah didukung dengan SOP yang jelas dan pemeriksaan rutin atas barang jaminan yang dilakukan secara fisik dan pencocokan pada buku catatan.

b. Evaluasi penerapan sistem pengendalian internal atas penerimaan barang jaminan dan pengeluaran kas masih ada kelemahan dalam pengendalian pada PT. Pegadaian (Persero) dimana masih ada rangkap jabatan dan otorisasi oleh pengelola UPC yaitu penaksir, pemegang gudang dan penyimpan barang jaminan hanya dilakukan oleh satu orang saja yaitu pengelola UPC.

c. Evaluasi penerapan sistem pengendalian internal atas pengembalian barang jaminan dan penerimaan kas masih terdapat kelemahan dalam pengendalian pada PT. Pegadaian (Persero) karena masih ada rangkap jabatan pada pengelola UPC sebagai pemegang gudang dan penyimpan barang jaminan.

d. Evaluasi penerapan sistem pengendalian internal atas pelelangan barang jaminan masih terdapat kelemahan dalam pengendalian pada PT. Pegadaian (Persero) dimana tidak ada dokumen yang diberikan baik kepada pembeli barang jaminan terjual, maupun nasabah yang barang jaminannya telah terjual.

\subsection{Saran}

Berdasarkan pada kesimpulan yang telah dipaparkan maka dikemukakan beberapa saran sebagai berikut.

a. Perlu adanya penaksir di UPC sehingga pengelola UPC tidak merangkap jabatan. Otorisasi harus dilakukan sesuai peraturan yang ada yaitu oleh penaksir dan pengelola UPC bukan hanya oleh pengelola UPC saja.

b. Barang Jaminan harus di simpan di dalam brangkas dan di catat dalam dokumen yang terkait setelah terjadi proses penerimaan barang jaminan sehingga meminimalisir kemungkinan terjadinya penyelewengan.

Pada proses pelelangan PT. Pegadaian (Persero) sebaiknya membuat bukti yang akan diserahkan kepada pihak pembeli sebagai bukti penerimaan uang dari pembeli dan kepada nasabah sekaligus sebagai bukti barang jaminan telah dilelang dan besarnya hasil penjualan dari barang lelang tersebut.

\section{DAFTAR PUSTAKA}

Akwaa Ellis K, 2016. Effect of Internal Controls on Credit Risk among Listed Spanish Banks. Omnia Science. ISSN 1697-9818. Vol. 12 No. 1. 357-389. 
Bahsan, M, 2010, Hukum Jaminan dan Jaminan Kredit Perbankan Indonesia, PT. Raja Grafindo Persada, Jakarta.

Firdaus, Rachmat, 2003, Teori dan Analisis Kredit serta Ketentuan-Ketentuan Tentang Beberapa Jenis Kredit, Purnasarana Lingga Utama, Bandung.

Kuncoro, Mudrajad, 2014. Metode Riset untuk Bisnis dan Ekonomi, Edisi 4. Erlangga. Jakarta.

Lakis V, 2012. The Concept of Internal Control System: Theoretical Aspect. Ekonomika, ISSN 1392-1258, Vol. 91 No. 2, 142-152.

Pemerintah Republik Indonesia, Kitab Undang-undang Hukum Perdata.

Pemerintah Republik Indonesia, Peraturan Menteri Negara BUMN Nomor Per01/MBU/2011 tentang Penerapan Tata Kelola Perusahaan Yang Baik (Good Corporate Governance) Pada Badan Usaha Milik Negara.

Pemerintah Republik Indonesia, Peraturan Pemerintah No. 103 Tahun 2000 tentang Perusahaan Umum (Perum) Pegadaian. Undang-undang No. 10 tahun 1998 tentang Perbankan. , Undang-undang No. 23 Tahun 1999 tentang Bank Indonesia.

PT. Pegadaian (Persero). 2012. Pedoman Operasional Kantor Cabang. PT. Pegadaian (Persero). Jakarta.

Provitiviti, 2014. The Updated COSO Internal Control Framework, FAQs. Second Edition. Provitiviti Inc, Washington, DC.

Romney B. Marshall dan Paul John Steinbart, 2006. Accounting Information System. Edisi Ke Sembilan. Salemba Empat. Jakarta.

Siwu, Fifke M. 2013. Evaluasi Penerapan Sistem Pengendalian Intern Atas Prosedur Penerimaan Dan Pengembalian Barang Jaminan pada PT. Pegadaian (Persero) Cabang Kalawat. Jurnal EMBA, ISSN 2303-1174, Vol. 1 No. 4, 1706-1716.

Teru, Susan P., 2015. Appraisal of Accounting Information System and Internal Control Frameworks. International Journal of Scientific and Research Publications, ISSN 2250-3153, Vol. 5 Issue 9, 1-3.

Topash, N. K., 2014. Evaluation of Efficiency of Accounting Information Systems: A Study on Mobile Telecommunication Companies in Bangladesh. Global Disclosure of Economics and Business, Vol. 3 No. 1, pp 40-55.

Oseifuah Emmanuel, 2015. Internal Control Systems in Small and Medium-sized Medical Practices in Thulamela Municipality, South Africa. Problems and Perspectives in Management. Vol. 13, Issue 4. 215-222 
Nasabah

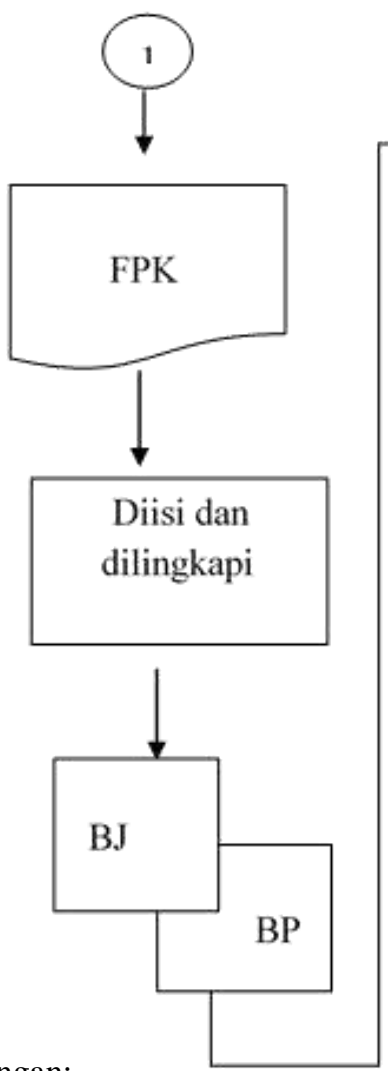

Keterangan:

FPK : Formulir Permintaan Kredit

BP : Bukti Pendukung (KTP/SIM)

BJ : Barang Jaminan

$\mathrm{Rp} \quad$ : Uang Tunai

BPBJ : Buku Penerimaan Barang Jaminan

SBK : Surat Bukti Kredit

BG : Buku Gudang

LP : Laporan Pinjaman

LHK : Laporan Harian Kas

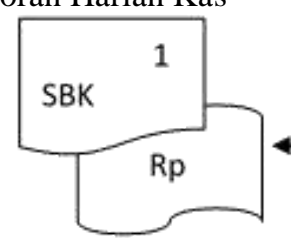

Penaksir/Penyimpan/Pengelola UPC

Kasir

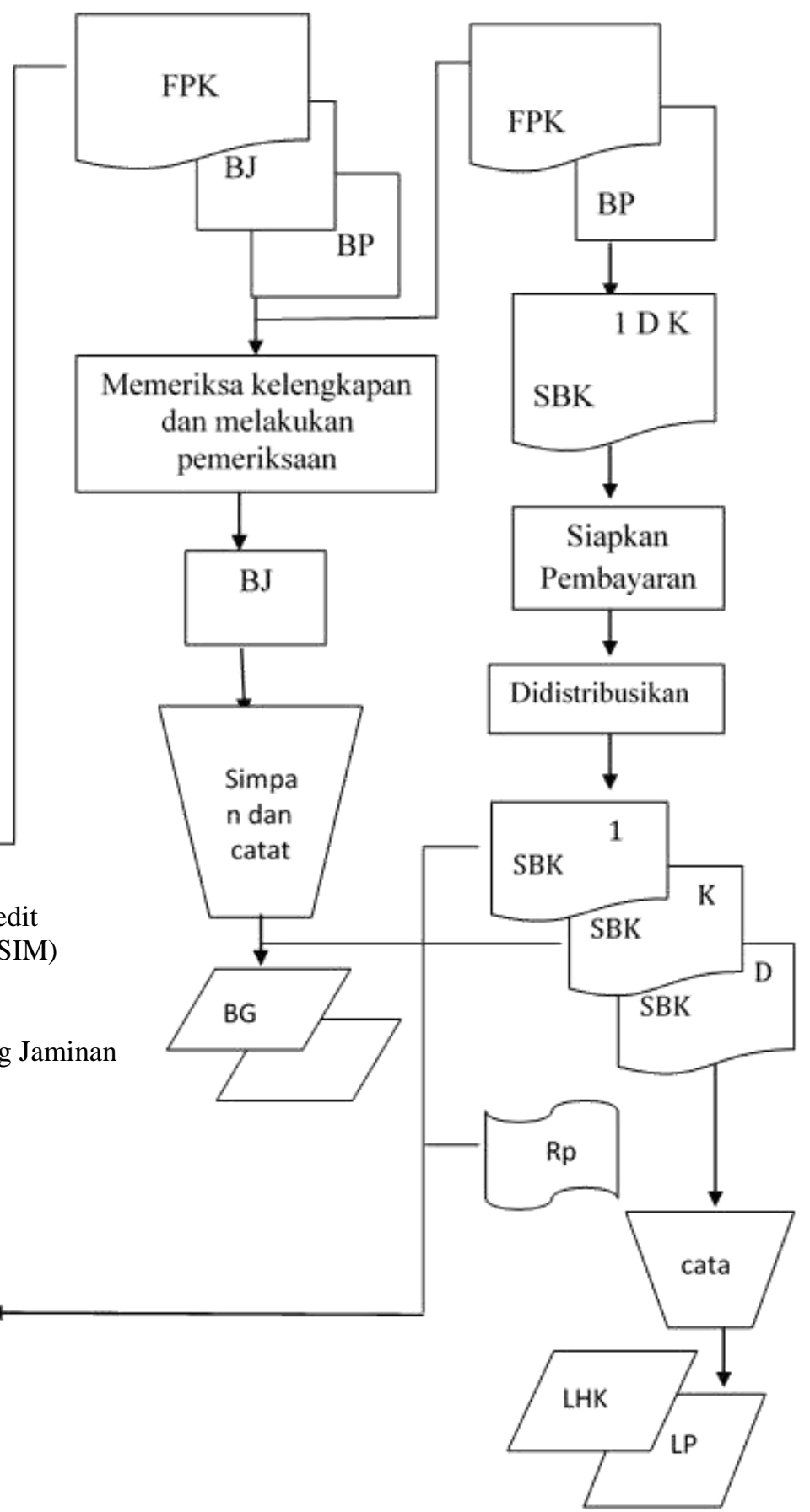

Gambar 1 flowchart penerimaan barang jaminan 


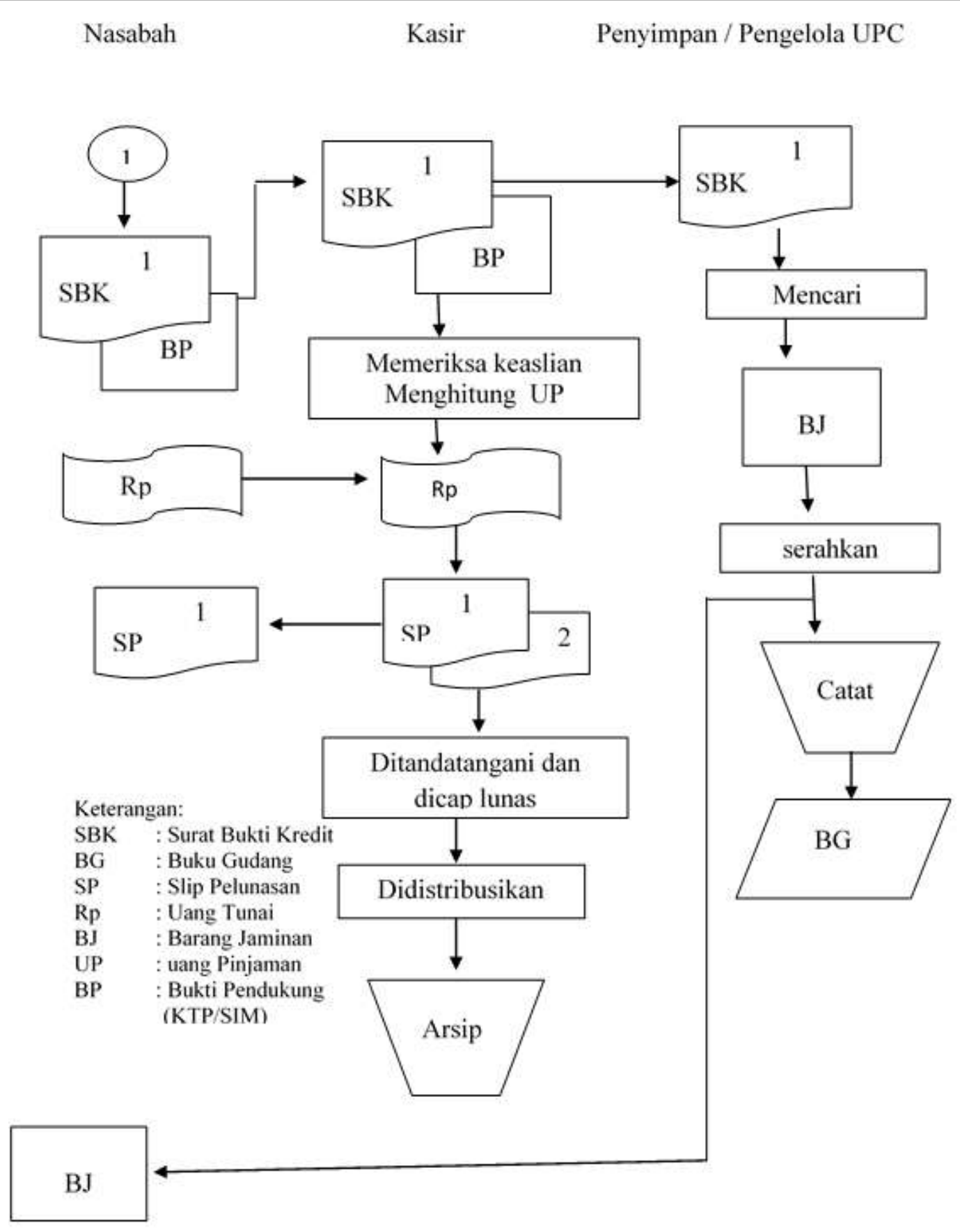

Gambar 2 Flowchart pengembalian barang jaminan 


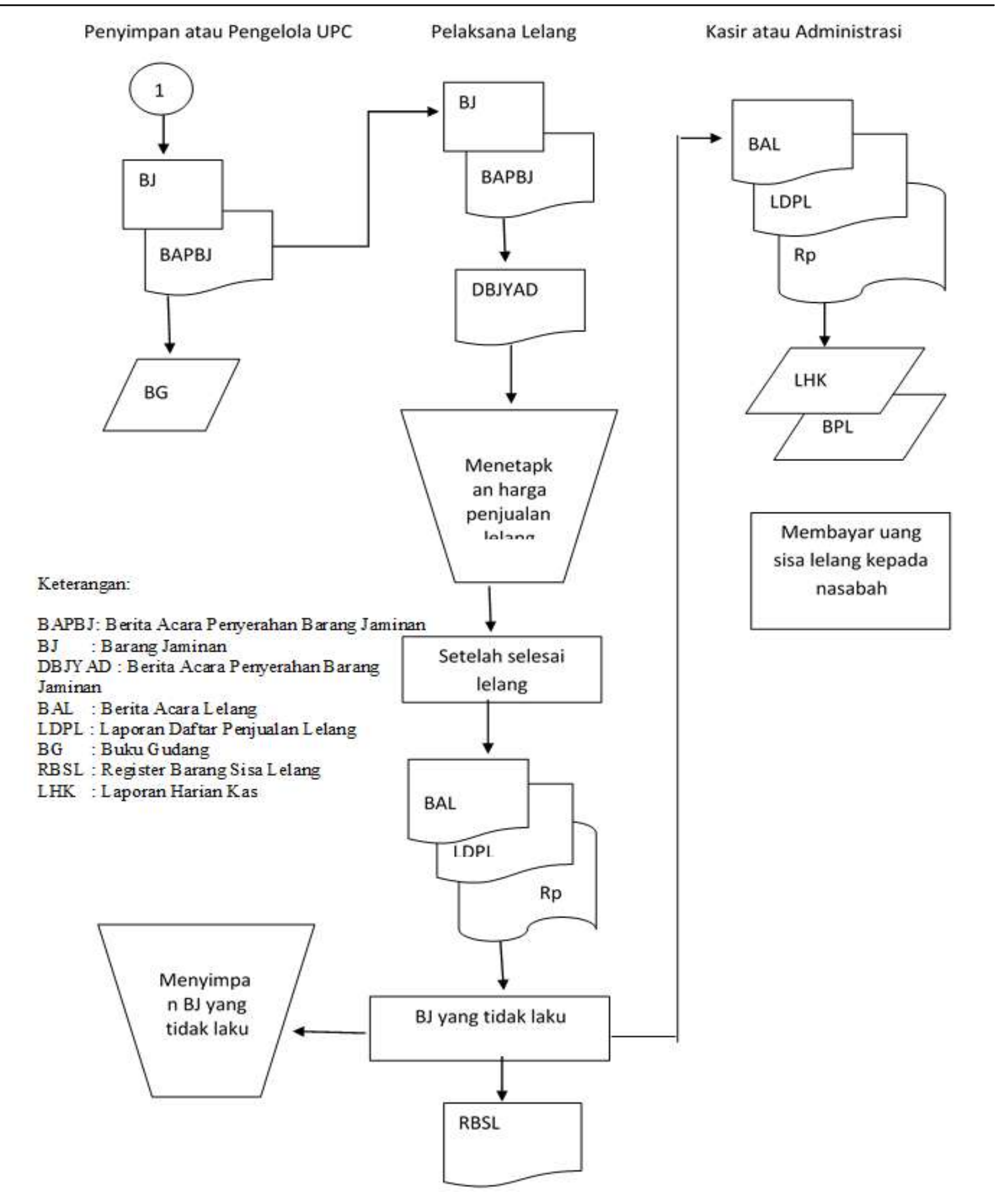

Gambar 3 flowchart pelelangan barang jaminan 